\title{
Pseudoaneurisma de artéria poplítea secundário a osteocondroma femoral - relato de caso
}

\author{
Popliteal artery pseudoaneurysm caused by a femoral osteochondorma - \\ case report
}

Fabricio Mascarenhas de Oliveira'; Nelson Fernandes Júnior ${ }^{2}$; Tasso Roberti3; Edgar Bolanho3;

Regina de Faria Bittencourt da Costa, TCBC- SP4

\section{INTRODUÇÃO}

$\mathrm{O}$ steocondroma é o tumor ósseo benigno mais comum, sendo encontrado em até $2 \%$ da população. Esses tumores têm uma cápsula protetora que sofre ossificação no período final do crescimento com o fechamento da epífise. Por este motivo, desenvolvem-se principalmente na adolescência. Pode ser único ou múltiplo e localiza-se nas metáfises ósseas, comumente no fêmur distal ${ }^{1-3}$.

Normalmente assintomático, achado casual de radiografia, pode estar associado à inúmeras complicações, incluindo deformidades do esqueleto, alterações do crescimento, compressões nervosas, limitação da mobilidade articular, fraturas do tumor e degeneração maligna.

Os autores relatam um caso de pseudoaneurisma de artéria poplítea como complicação vascular do osteocondroma de fêmur.

\section{RELATO DO CASO}

ASG, masculino, 30 anos de idade, com relato de três cirurgias prévias em fêmur esquerdo por tumor foi encaminhado ao Serviço de Cirurgia Vascular com claudicação limitante do membro inferior esquerdo para $100 \mathrm{~m}$, com piora progressiva há dois anos e tumor pulsátil e indolor na região do joelho esquerdo (Figura 1A) de crescimento lento e progressivo. Ao exame ausência de sopros, hipertermia ou sinais de insuficiência venosa crônica, associados à diminuição dos pulsos tibiais.

Radiografia de fêmur esquerdo - imagem sugestiva de osteocondroma de metáfise medial de fêmur (Figura 1B); ecodoppler arterial - pseudoaneurisma de artéria poplítea sem fistula artério-venosa; tomografia de membro inferior esquerdo - imagem sugestiva de aneurisma ou pseudoaneurisma de artéria poplítea em íntimo contato com tumor ósseo em metáfise de fêmur (Figura 1C); arteriografia - ectasia de artéria poplítea sugestiva de aneurisma ou pseudoaneurisma deste segmento, sem oclusão de artérias de perna (Figura 1D).
Exploração cirúrgica com incisão ântero-medial, ao nível do canal dos adutores, evidenciou tumor pulsátil, de aproximadamente $10 \mathrm{~cm}$ de comprimento e $4 \mathrm{~cm}$ de diâmetro, com espícula óssea exuberante em metáfise medial do fêmur.

Optou-se pela abertura do pseudoaneurisma com rafia simples dos dois orifícios fistulosos e ressecção da exostose (Figura 2A).

Evolução pós-operatória sem claudicação limitante e/ou tumor, presença de pulsos tibiais, alta hospitalar assintomático. Exame anátomo-patológico confirmou a hipótese de osteocondroma de fêmur.

Arteriografia de controle após seis meses de cirurgia sem sinais de tumoração em artéria poplítea esquerda e com perviedade de artérias tibiais (Figura 2B). Permanece assintomático após três anos, seguimento com radiografia simples e ecodoppler.

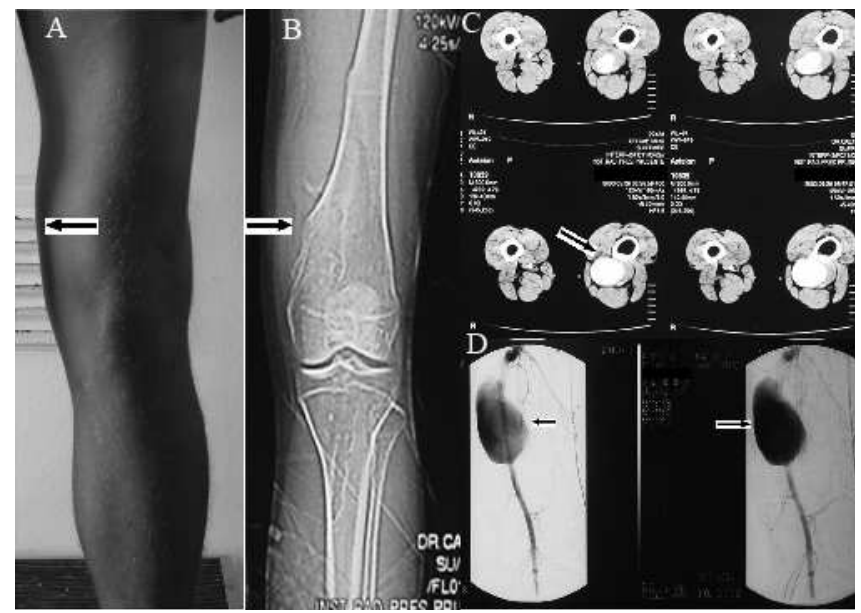

Figura 1 - A) tumoração localizada em face medial do joelho esquerdo (seta); B) radiografia com imagem sugestiva de osteocondroma de metáfise medial de fêmur (seta); C) imagem sugestiva de aneurisma ou pseudoaneurisma de artéria poplítea em íntimo contato com tumoração óssea em metáfise de fêmur (seta); D) ectasia de artéria poplítea sugestiva de aneurisma ou pseudoaneurisma deste segmento.

1. Ex-Médico Residente de Cirurgia Vascular - Hospital Heliópolis - SP; 2. Médico Assistente do Serviço de Cirurgia Vascular - Hospital Heliópolis -SP; 3. Médico Assistente de Cirurgia Vascular - Hospital Heliópolis - SP; 4. Chefe do Serviço de Cirurgia Vascular - Hospital Heliópolis. - SP. 

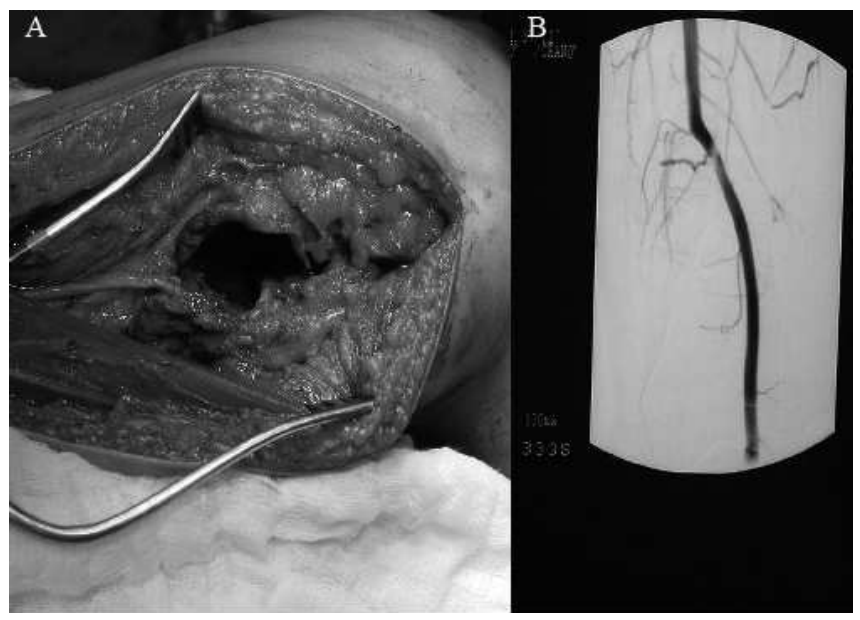

Figura 2 - A) exploração cirúrgica evidenciando pseudoaneurisma; B) arteriografia de controle sem evidência de pseudoaneurisma.

\section{DISCUSSÃO}

As lesões vasculares secundárias aos osteocondromas são raras e desenvolvem-se, na sua maioria, na segunda década de vida ${ }^{3}$. As complicações arteriais são responsáveis por $91 \%$ dos casos, sendo o mais comum o pseudoaneurisma $(63,9 \%)$.

A artéria poplítea é o local mais frequente de formação de pseudoaneurismas, provavelmente pela relativa fixação no canal adutor e na fossa poplítea. O outro motivo é a maior ocorrência de osteocondromas no fêmur distal e na tíbia proximal.

Acredita-se que o trauma físico pela fricção durante a extensão e flexão da perna, levando à fraqueza da parede arterial pelo tumor em crescimento, seja mecanismo associado à formação de pseudoaneurismas. Outro fator potencialmente relacionado é a punção direta da espícula óssea no vaso adjacente ${ }^{4}$.

Como a maioria dos osteocondromas é assintomática, o tratamento cirúrgico é controverso ${ }^{4,5}$, sendo indicado quando há complicações (embolia arterial, trombose venosa, flebite) e/ou quando próximos a feixes vásculonervosos.

O tratamento do pseudoaneurisma associado ao osteocondroma é cirúrgico: correção do pseudoaneurisma associado à ressecção da espícula óssea ${ }^{1-4}$. Pode se reconstruir a lesão arterial com enxerto venoso ou protético, secção do pseudoaneurisma com anastomose término-terminal da artéria, ou simples sutura do orifício responsável pelo pseudoaneurisma, como no relato de caso descrito ${ }^{4}$.

\section{A $B$ S $S$ T R A C}

Osteochondromas are the most common benign tumor of the bone. They are sometimes responsible for vascular complications involving either veins or arteries, principally around the knee. Pseudoaneurysms are considered a rare condition. The authors describe the occurrence of a pseudoaneurysm of the popliteal artery in association with a femoral osteochondroma in a 30-yearsold man.

Key words: Pseudoaneurysm. Popliteal artery. Osteochondroma surgery.

\section{REFERÊNCIAS}

1. Cardon A, Aillet S, Ledu J, Kerdiles Y. Pseudo-aneurysm of the popliteal artery by femoral exostosis in a young child. J Cardiovasc Surg. 2001;:42(2):241-4

2. Matsushita M, Nishikimi N, Sakurai T, Nimura Y. Pseudoaneurysm of the popliteal artery caused by exostosis of the femur: case report and review of the literature. J Vasc Surg. 2000;32(1):2014.

3. Vasseur MA, Fabre O. Vascular complications of osteochondromas J Vasc Surg. 2000;31(3):532-8.

4. Perez-Burkhardt JL, Gómez Castilla JC. Postraumatic poplitea pseudoaneurysm from femoral osteochondroma: case report and review of the literature. J Vasc Surg. 2003;37(3):669-71.

5. Wiater JM, Farley FA. Popliteal pseudoaneurysm caused by an adjacent osteochondroma: a case report and review of the literature. Am J Orthop. 1999:28(7):412-6.
Recebido em 10/04/2007

Aceito para publicação em 22/05/2007

Conflito de interesse: nenhum

Fonte de financiamento: nenhum

\section{Como citar este artigo:}

Oliveira FM, Fernandes Júnior N, Roberti T, Bolanho E, Costa RFB. Pseudoaneurisma de artéria poplítea secundário à osteocondroma femoral - relato de caso. Rev Col Bras Cir. [periódico na Internet] 2012; 39(6). Disponível em URL: http://www.scielo.br/rcbc

\section{Endereço para correspondência:}

Regina de Faria Bittencourt da Costa

E-mail: costara@uol.com.br 